Research Article

\title{
Comparative study of the efficacy and safety of olopatadine eyedrops and sodium cromoglycate in clinical practice: a prospective study
}

\author{
Scandashree K.*, Meghana Patil, Padmaja Udaykumar
}

Department of Pharmacology, Father Muller Medical College, Mangalore, Karnataka, India

Received: 16 August 2016 Accepted: 20 August 2016

*Correspondence to:

Dr. Scandashree K., Email: padmajaudaykumar@ gmail.com

Copyright: () the author(s), publisher and licensee Medip Academy. This is an openaccess article distributed under the terms of the Creative Commons Attribution NonCommercial License, which permits unrestricted noncommercial use, distribution, and reproduction in any medium, provided the original work is properly cited.

\begin{abstract}
Background: Allergic eye diseases are the commonest causes of ocular morbidity worldwide. To choose the best therapy in allergic conjunctivitis, understanding of underlying mechanisms implicated in triggering the allergy is very important. Olopatadine with a wide spectrum has proven to be very effective in allergic conjunctivitis. The objective of the study was to compare the efficacy and safety of ophthalmic solutions of olopatadine $0.2 \%$ once daily, olopatadine $0.1 \%$ twice daily and sodium cromoglycate $2 \%$ four times daily in allergic conjunctivitis for 3 weeks.

Methods: This was a prospective, single centre study enrolling 304 patients with allergic conjunctivitis attending ophthalmology clinics. Subjects were assessed for ocular signs and symptoms at 3 visits-baseline, week 2 , week 3 . The change from baseline in the mean scores of itching and redness at 3 weeks was primary outcome variable.

Results: The reduction in signs and symptoms were statistically significant in all the three groups $(\mathrm{p}<0.001)$. Both the olopatadine receiving groups were better than sodium cromoglycate receiving group in reducing ocular signs and symptoms by pairwise comparison by wilcoxon signed rank test.

Conclusions: Olopatadine ophthalmic solution is better than sodium cromoglycate ophthalmic solution in reducing the ocular signs and symptoms in allergic conjunctivitis.
\end{abstract}

Keywords: Olopatadine, Allergic conjunctivitis, Sodium cromoglycate

\section{INTRODUCTION}

Allergic conjunctivitis in India, stands as the second most common reasons of ocular morbidity and comprise almost $15-20 \%$ cases attending ophthalmology clinics. ${ }^{1}$ It is one of the most common reasons for school absenteeism in children because of its distressful symptoms. $^{2,3}$

Allergic diseases of eye can be of acute or chronic type. ${ }^{4}$ Among them, seasonal allergic conjunctivitis (SAC) and perennial allergic conjunctivitis (PAC) are of acute type (IgE mediated) and are the most frequent forms of allergic conjunctival diseases. ${ }^{4}$ Mast cell degranulation is the result of exposure of an allergen to a sensitized mast cell. The subsequent release of many inflammatory mediators give rise to the signs and symptoms of $\mathrm{AC}$; among those, conjunctival congestion and ocular itching are mainly because of the action of histamine on $\mathrm{H} 1$ receptors.

In chronic allergic conditions like vernal keratoconjunctivitis (VKC), atopic keratoconjunctivitis (AKC) and giant papillary conjunctivitis (GPC), the pathophysiology is quite complex as there is a constant inflammatory response due to predominance of eosinophils and cytokine release mediated by Th2 cells. ${ }^{5,6}$

The pharmacologic agents that are available as ophthalmic solutions, used in the treatment of allergic conjunctivitis belong to diverse classes: 
- Antihistaminics: They block H1 histaminergic receptors. e.g. levocabastine, azelastine, bepostatine, alcaftadine.

- Mast cell stabilizers: They increase the calcium influx to the mast cell and thus maintains the stability of membrane and thus preventing degranulation of mast cells e.g. sodium cromoglycate, nedocromil sodium, lodoxamide. ${ }^{7}$

- Dual acting agents: Have both antihistaminic and mast cell stabilizing properties e.g. olopatadine, ketotifen, azelastine, epinastine.

- Non-steroidal anti-inflammatory drugs e.g. ketorolac, diclofenac, flurbiprofen.

- Corticosteroids: E.g. prednisolone, hydrocortisone, fluromethalone, loteprednol, desonide. In severe cases even immunomodulatory agents are used. ${ }^{5}$ The drugs preferred for the treatment of allergic conjunctivitis depends on the clinical severity of allergic conjunctivitis. ${ }^{8}$

Olopatadine hydrochloride is a promising dual action agent with a broad range of pharmacological effects. It revealed a higher affinity towards $\mathrm{H} 1$ receptor compared to $\mathrm{H} 2$ and $\mathrm{H} 3$ receptors and its selectivity towards $\mathrm{H} 1$ receptor was superior to other ocular antihistamines like ketotifen, levocabastine and pheniramine. ${ }^{9}$ In a concentration-dependent manner, it has shown to inhibit the release of histamine, tryptase and $\mathrm{PGD}_{2}{ }^{10}$ Olopatadine does not interact much with membrane phospholipids as it has a very low intrinsic surface activity because of which there is less cell membrane disruption and subsequent release of histamine, LDH, hemoglobin and other chemical mediators and thus have less discomfort on instillation. ${ }^{11}$ It has shown to inhibit TNF alfa release from conjunctival mast cells, and also suppress phosphatidylinositol turnover induced by histamine and secretion of IL- 6 and IL-8. ${ }^{12-14}$

The efficacy and tolerability of olopatadine $0.1 \%$ ophthalmic solution BD for 2-4 weeks have been demonstrated in several comparative studies on allergic conjunctivitis patients. ${ }^{15,16}$ Olopatadine $0.2 \%$ ophthalmic solution is being used recently and is found to be a safe and effective medication for the reduction of itching and has a duration of action of up to $24 \mathrm{~h}$ allowing for oncea-day dosing. ${ }^{17}$ The efficacy of twice a day dosing of olopatadine $0.1 \%$ has been compared to once daily dosing of olopatadine $0.2 \%$ in the prevention of ocular itching associated with allergic conjunctivitis over 24 hours in a CAC study. ${ }^{18}$ In order to assess the ability of olopatadine $0.2 \%$ in maximum prevention of ocular signs and symptoms in allergic conjunctivitis patients in a real clinical setting this study was undertaken. This study aims at comparing the efficacy and tolerability of olopatadine $0.2 \%$ ophthalmic solution administered OD and olopatadine hydrochloride $0.1 \%$ ophthalmic solution
BD along with sodium cromoglycate as standard in allergic conjunctivitis patients for 3 weeks. The objective of the study was to compare the efficacy and tolerability of olopatadine hydrochloride $0.2 \%$ ophthalmic solution OD, olopatadine hydrochloride $0.1 \%$ ophthalmic solution $\mathrm{BD}$ and sodium cromoglycate $2 \%$ QID administered for 3 weeks in allergic conjunctivitis.

\section{METHODS}

\section{Study design}

This study was a prospective study conducted in the Ophthalmic OPD, Father Muller Medical College Hospital, Mangalore from December 2014 to April 2015. The study protocol was approved by Institutional ethics committee. The present study enrolled 304 subjects with the mean (SD) age of 26.98(14.72)years.

\section{Inclusion and exclusion criteria}

All patients aged > 4 years with clinically diagnosed allergic conjunctivitis attending ophthalmic clinics with moderate to severe degree of clinical presentation were included in the study. Subjects with ocular surface disorders like pterygium, dry eye etc. were excluded from the study. Patients who have known hypersensitivity to the study drugs including benzalkonium chloride which is used as preservative in the ophthalmic solutions were excluded. If the patient has used the study medications from 1 week before the start of the study and patients who were to discontinue contact lens during study period were excluded. Pregnancy and lactation were also exclusion criteria of our study.

\section{Method of data collection}

A written informed consent was taken from all the patients who fulfilled the inclusion and exclusion criteria. Participant's demographic details and necessary medical and ocular details was taken at baseline. Enrolled subjects were prescribed different topical ophthalmic solutions by ophthalmologists; olopatadine hydrochloride $0.2 \%$ ophthalmic solution OD (group 1), olopatadine hydrochloride $0.1 \%$ ophthalmic solution $\mathrm{BD}$ (group 2)and sodium cromoglycate $2 \%$ ophthalmic solution QID(group 3 ) and were followed up for 6 weeks. Patient assessment was done at visit 1(at baseline), visit 2 (at week 2) and visit 3 (at week 3 ) during which they were examined for ocular signs and symptoms. The ocular signs assessed were conjunctival congestion, chemosis, lid edema using slit lamp biomicroscope that was graded according to the severity (grade 0 -absent, grade1-mild, grade 2-moderate, grade 3 severe) by the ophthalmologist; and ocular symptoms assessed were itching, discomfort, foreign body sensation, stinging, photophobia, and watering (grade 0-absent, grade1-mild, grade 2-moderate, grade 3 severe) by interviewing the patients. Adverse events were noted during subsequent visit 2 and visit 3. 


\section{Outcome measures}

The primary outcome measure was change from baseline (CFB) in the mean scores of itching and redness at 3rd visit (week 3 ). The secondary outcome measures included CFB in mean scores of itching and redness at visit 2 and treatment related adverse events.

\section{Statistical analysis}

Statistical analyses were performed using SPSS version 19.0. Data was tabulated in excel. Statistical tests used to analyze the results were friedman test, wilcoxon signed rank tests. $\mathrm{P}$ value $<0.05$ was considered statistically significant.

\section{RESULTS}

This study enrolled a total of 310 subjects out of which 304 completed the study for 3 weeks. 105 subjects received olopatadine hydrochloride $0.2 \%$ ophthalmic solution OD (group 1), 98 subjects received olopatadine hydrochloride $0.1 \%$ ophthalmic solution BD (group 2) and 101 subjects received sodium cromoglycate $2 \%$ ophthalmic solution QID (group 3). The study consisted of 92 females and 212 males. Table 1 shows the baseline characteristics of subjects in the study. Table 2 shows the mean scores for ocular ocular itching and conjunctival congestion in allergic conjunctivitis at each examination. There was no significant difference among the groups regarding baseline scores of conjunctival congestion, ocular itching, ocular discomfort, stinging and photophobia.

Table 1: Baseline characteristics of allergic conjunctivitis patients in the study.

\begin{tabular}{|c|c|c|c|c|}
\hline Parameters & & $\begin{array}{l}\text { Olopatadine } 0.2 \% \text { OD } \\
(\mathrm{N}=105)\end{array}$ & $\begin{array}{l}\text { Olopatadine } 0.1 \% \text { BD } \\
(\mathrm{N}=98)\end{array}$ & $\begin{array}{l}\text { Sodium cromoglycate } 2 \% \\
\text { QID }(\mathrm{N}=101)\end{array}$ \\
\hline \multirow{3}{*}{ Age } & Mean(SD) & $33.51(15.49)$ & 25.1(13.4) & 22.01(12.6) \\
\hline & $<16 y r s$ & 16 & 26 & 32 \\
\hline & $>16 \mathrm{yrs}$ & 89 & 72 & 69 \\
\hline \multirow{2}{*}{ Sex } & Male & 73 & 66 & 73 \\
\hline & Female & 32 & 32 & 28 \\
\hline $\begin{array}{l}\text { Allergic } \\
\text { conjunctivitis }\end{array}$ & & 105 & 98 & 101 \\
\hline
\end{tabular}

Table 2: Mean scores of ocular signs and symptoms.

\begin{tabular}{|llllllllllllll|}
\hline & \multicolumn{4}{c}{ Olopatadine $\mathbf{0 . 2 \%}$ OD } & \multicolumn{3}{c|}{ Olopatadine $\mathbf{0 . 1 \%}$ BD } & \multicolumn{3}{c|}{ Sodium cromoglycate 2\% QID } \\
\hline VARIABLE & $\begin{array}{l}\text { Visit } \\
1\end{array}$ & $\begin{array}{l}\text { Visit } \\
2\end{array}$ & $\begin{array}{l}\text { Visit } \\
3 \dagger\end{array}$ & $\begin{array}{l}\text { Friedman } \\
\text { test value }\end{array}$ & $\begin{array}{l}\text { Visit } \\
1\end{array}$ & $\begin{array}{l}\text { Visit } \\
\text { Visit }\end{array}$ & $\begin{array}{l}\text { Friedman } \\
\text { test value }\end{array}$ & $\begin{array}{l}\text { Visit } \\
1\end{array}$ & $\begin{array}{l}\text { Visit } \\
2\end{array}$ & $\begin{array}{l}\text { Visit } \\
3 \dagger\end{array}$ & $\begin{array}{l}\text { Friedman } \\
\text { test value }\end{array}$ \\
\hline Itching & 3.67 & 1.65 & 0.50 & 208 & 3.66 & 1.42 & 0.35 & 195.5 & 3.51 & 2.62 & 1.46 & 183 & \\
\hline $\begin{array}{l}\text { Conjunctival } \\
\text { congestion }\end{array}$ & 3.67 & 2.3 & 1.18 & 207.5 & 3.73 & 2.18 & 1.14 & 195 & 3.63 & 3.00 & 2.28 & 145.079 \\
\hline
\end{tabular}

$\uparrow \mathrm{P}$ value was $<0.001$

Table 3: Change from baseline in the mean scores of ocular itching and conjunctival congestion at week 3.

\begin{tabular}{|lllllll|}
\hline & \multicolumn{3}{c}{ Ocular itching } & \multicolumn{3}{c|}{ Conjunctival congestion } \\
& $\begin{array}{l}\text { Olopatadine } \\
0.2 \% \text { OD }\end{array}$ & $\begin{array}{l}\text { Olopatadine } \\
0.1 \% \text { BD }\end{array}$ & $\begin{array}{l}\text { Sodium cromoglycate } \\
2 \% \text { QID }\end{array}$ & $\begin{array}{l}\text { Olopatadine } \\
0.2 \% \text { OD }\end{array}$ & $\begin{array}{l}\text { Olopatadine } \\
0.1 \% \text { BD }\end{array}$ & $\begin{array}{l}\text { Sodium } \\
\text { cromoglycate } \\
2 \% \text { QID }\end{array}$ \\
\hline $\begin{array}{l}\text { Change from baseline } \\
\text { (mean difference) }\end{array}$ & 3.163 & 3.316 & 2.059 & 2.486 & 2.592 & 1.356 \\
\hline Change (\%) & 86.36 & 90.53 & 58.59 & 67.79 & 69.4 & 37.33 \\
\hline
\end{tabular}

Table 4: Between group comparisons using wilcoxon signed rank test.

\begin{tabular}{|lllllll|}
\hline & Ocular itching & & \multicolumn{4}{c|}{ Conjunctival congestion } \\
& $\begin{array}{l}\text { Between } \\
\text { group 1 and } \\
\text { group 2 }\end{array}$ & $\begin{array}{l}\text { Between } \\
\text { group 1 and } \\
\text { group 3 }\end{array}$ & $\begin{array}{l}\text { Between group } \\
\text { 2 and group 3 }\end{array}$ & $\begin{array}{l}\text { Between } \\
\text { group 1 and } \\
\text { group 2 }\end{array}$ & $\begin{array}{l}\text { Between group } \\
\text { 1 and group 3 }\end{array}$ & $\begin{array}{l}\text { Between group 2 } \\
\text { and group 3 }\end{array}$ \\
\hline P value & 0.085 & 0.000 & 0.000 & 0.137 & 0.000 & 0.000 \\
\hline
\end{tabular}


The mean scores of all the parameters significantly reduced at visit 2 and visit $3(\mathrm{P}<0.001)$ in all the 3 groups. Therefore both olopatadine and sodium cromoglycate ppthalmic solutions were effective in alleviating signs and symptoms of AC. Table 3 shows change from baseline (CFB) in the mean scores and percent change in ocular itching and conjunctival congestion at week 3 . The difference in the CFB in the mean scores of itching and redness between the three groups was statistically significant at week 3 . Wilcoxon signed rank test was done to know exactly between which groups results were statistically significant. Thus group A and group B showed statistically significant difference from group $\mathrm{C}$, whereas there was no statistically significant difference between groupA and group B. Therefore olopatadine receiving groups showed better efficacy than sodium cromoglycate receiving group showing that once daily olopatadine $0.2 \%$ or twice daily olopatadine $0.1 \%$ was better than sodium cromoglycate $2 \%$ QID in allergic conjunctivitis. There was no statistically significant difference in the CFB in mean scores of itching and redness between once daily olopatadine $0.2 \%$ or twice daily olopatadine $0.1 \%$ at week 3. There were no treatment related adverse events reported during the study.

\section{DISCUSSION}

There are a wide range of pharmacological agents that are available for use in the prevention of ocular signs and symptoms in allergic conjunctivitis which include antihistaminics, mast cell stabilizers, non-steroidal antiinflammatory drugs and corticosteroids. The choice of the drug for the treatment of allergic conjunctivitis is based upon the clinical severity. ${ }^{19}$ New antiallergic ophthalmic solutions like olopatadine, epinastine, ketotifen, having a spectrumof pharmacological actions are available recently, where as sodium cromoglycate is an old drug.

The efficacy of olopatadine $0.1 \% \quad \mathrm{BD}$ in allergic conjunctivitis has been demonstrated in multiple studies including the conjunctival allergen challenge (CAC) model. ${ }^{20-22}$ According to aguilar et al olopatadine $0.1 \%$ shows superior efficacy in the rapid resolution of the signs and symptoms of allergic conjunctivitis. ${ }^{23}$ Patient preference for olopatadine is also better compared to ketotifen. $^{24}$ In the CAC studies, olopatadine $0.1 \%$ twice daily was found to be more efficient than epinastine and loteprednol etabonate $0.2 \%$ in decreasing the signs and symptoms of allergic conjunctivitis such as itching, redness and chemosis. ${ }^{21,25}$ In the in-vivo conjunctival allergen challenge (CAC) model in allergic individuals, olopatadine reduced tear levels of histamine and various other aspects of allergic inflammation. ${ }^{26,27}$

The efficacy of two doses of olopatadine $0.1 \%$ has been compared to one dose of olopatadine $0.2 \%$ in the prevention of itching associated with allergic conjunctivitis over 24 hours in a CAC study, did not show any statistically significant difference between the two groups. ${ }^{18}$ Olopatadine has shown a greater economic benefit over sodium cromoglycate in treatment of allergic conjunctivitis. $^{28}$ A randomized controlled trial by the International olopatadine study group has shown that olopatadine $0.1 \%$ BD had a better efficacy when compared to sodium cromoglycate $2 \%$ QID in reducing conjunctival congestion and itching. ${ }^{16}$ Most of the studies have compared $0.1 \%$ olopatadine administered twice daily; but in our study, we used recently recommended $0.2 \%$ ophthalmic solution of olopatadine which can be administered once daily as it can improve the patient compliance and compared with olopatadine $0.1 \%$ twice daily and sodium cromoglycate $2 \%$ administered four times daily in allergic conjunctivitis patients. Olopatadine hydrochloride $0.1 \%$ ophthalmic solution is administered as 1-2 drops twice daily in allergic conjunctivitis. However, in Japan it is approved as 1-2 drops four times a day on the basis that higher frequency may have better antigen flushing effect. ${ }^{8}$

This was not a randomized and blinded study which is the major limitation of the study. Future studies should be conducted as RCTs with more sample size to generalize the results to the general population. According to the study results, both the treatments were effective in reducing the scores of signs and symptoms of allergic conjunctivitis. But olopatadine was superior to sodium cromoglycate. Thus, olopatadine $0.2 \%$ OD and olopatadine $0.1 \%$ BD were better compared to sodium cromoglycate $2 \%$ QID in reducing itching and redness at week 3 in allergic conjunctivitis patients.

\section{CONCLUSION}

To choose the best therapy in allergic conjunctivitis, understanding of underlying mechanisms implicated in triggering the allergy is very important. Olopatadine with a wide spectrum has proven to be very effective in allergic conjunctivitis. Thus, Olopatadine $0.2 \%$ OD and/or olopatadine $0.1 \%$ BD are a better choice compared to sodium cromoglycate $2 \%$ QID in reducing itching and redness at week 3 in moderate allergic conjunctivitis patients.

\section{Funding: No funding sources \\ Conflict of interest: None declared}

Ethical approval: The study was approved by the Institutional Ethics Committee

\section{REFERENCES}

1. Biswas J, Saha I, Das D, Bandyopadhyay S, Ray B, Biswas G. Ocular morbidity among children at a tertiary eye care hospital in Kolkata, West Bengal. Indian J Public Health. 2012;56(4):293.

2. Chakraborti C, Mallik S, Choudhury KP, Das J. Childhood ocular morbidity in Eastern India: a tertiary hospital study. Sudanese J Public Health. 2012;7(4):126-30. 
3. Kamath PBT, Prasad BS, Deepthi R, Muninrayana C. Prevalence of ocular morbidity among school going children (6-15years) in rural area of Karnataka, South India. Int J Pharm Biomed Res. 2012;3(4):209-12.

4. McGill JI, Holgate ST, Church MK, Anderson DF, Bacon A. Allergic eye disease mechanisms. Br J Ophthalmol. 1998;82(10):1203-14.

5. Leonardi A, De dominicis, Motterle L. Immunopathogenesis of ocular allergy: a schematic approach to different clinical entities. Curr Opin Allergy Clin Immunol. 2007;7(5):429-35.

6. Mishra GP, Tamboli V, Jwala J, Mitra AK. Recent patents and emerging therapeutics in the treatment of allergic conjunctivitis. Recent Pat Inflamm Allergy Drug Discov. 2011;5(1):26-36.

7. Rosa M, Lionetti E, Reibaldi M, Russo A, Longo A, Leonardi S, et al. Allergic conjunctivitis: a comprehensive review of the literature. Ital J Pediatr. 2013;39:18.

8. Uchio E. Treatment of allergic conjunctivitis with olopatadine hydrochloride eye drops. Clin Ophthalmol. 2008;2(3):525-31.

9. Sharif NA, Xu SX, Miller ST, Gamache DA, Yanni JM. Characterization of the ocular antiallergic and antihistaminic effects of olopatadine (AL-4943A), a novel drug for treating ocular allergic diseases. J Pharmacol Exp Ther. 1996;278(3):1252-61.

10. Sharif NA, Xu SX, Yanni JM. Olopatadine (AL4943A): ligand binding and functional studies on a novel, long acting $\mathrm{H} 1$-selective histamine antagonist and anti-allergic agent for use in allergic conjunctivitis. J Ocul Pharmacol Ther. 1996;12(4):401-7.

11. Brockman HL, Momsen MM, Knudtson JR, Miller ST, Graff G, Yanni JM. Interactions of olopatadine and selected antihistamines with model and natural membranes. Ocul Immunol Inflamm. 2003;11(4):247-68.

12. Cook EB, Stahl JL, Barney NP, Graziano FM. Olopatadine inhibits $\mathrm{TNF} \alpha$ release from human conjunctival mast cells. Annals of Allergy, Asthma and Immunology. 2000;84(5):504-8.

13. Yanni JM, Weimer LK, Sharif NA, Xu SX, Gamache DA, Spellman JM. Inhibition of histamine-induced human conjunctival epithelial cell responses by ocular allergy drugs. Arch Ophthalmol. 1999;117(5):643-7.

14. Yanni JM, Stephens DJ, Miller ST, Weimer LK, Graff G, Parnell D, et al. The in vitro and in vivo ocular pharmacology of olopatadine (AL-4943A), an effective anti-allergic/antihistaminic agent. J Ocul Pharmacol Ther. 1996;12(4):389-400.

15. Butrus S, Greiner JV, Discepola M, Fingold I. Comparison of the clinical efficacy and comfort of olopatadine hydrochloride $0.1 \%$ ophthalmic solution and nedocromil sodium $2 \%$ ophthalmic solution in the human conjunctival allergen challenge model. Clin Ther. 2000;22:1462-72.
16. Katelaris CH, Ciprandi G, Missotten L, Turner FD, Bertin D, Berdeaux G. International olopatadine study group. a comparison of the efficacy and tolerability of olopatadine hydrochloride $0.1 \%$ ophthalmic solution and cromolyn sodium $2 \%$ ophthalmic solution in seasonal allergic conjunctivitis. Clin Ther. 2002;24(10):1561-75.

17. Abelson MB, Gomes PJ. Olopatadine $0.2 \%$ ophthalmic solution: the first ophthalmic antiallergy agent with once-daily dosing. Expert Opin Drug Metab Toxicol. 2008;4(4):453-61.

18. Abelson MB, Spangler DL, Epstein AB, Mah FS, Crampton HJ. Efficacy of once-daily olopatadine $0.2 \%$ ophthalmic solution compared to twice-daily olopatadine $0.1 \%$ ophthalmic solution for the treatment of ocular itching induced by conjunctival allergen challenge. Curr Eye Res. 2007;32(12):101722.

19. Friedlaender MH. Epinastine in the management of ocular allergic disease. Int Ophthalmol Clin. 2006;46(4):85-6.

20. Avunduk AM, Tekelioglu Y, Turk A, Akyol N. Comparison of effects of ketotifen fumarate $0.025 \%$ and olopatadine HCI $0.1 \%$ ophthalmic solutions in seasonal allergic conjunctivitis: a 30-day, randomized, double-masked, artificial tear substitute-controlled trial. Clin Ther. 2005;27:1392402.

21. Berdy GJ, Stoppel JO, Ebstein AB. Comparison of the clinical efficacy and tolerability of olopatadine hydrochloride $0.1 \%$ ophthalmic solution and loteprednol etabonate $0.2 \%$ ophthalmic suspension in the conjunctival allergen challenge model. Clin Ther. 2002;24:918-29.

22. Kamis U, Ozturk BT, Ozkagnici A, Gunduz K. Comparison of the efficacy of olopatadine hydrochloride $0.1 \%$ ophthalmic solution and artificial tears in seasonal allergic conjunctivitis. Acta Ophthalmol Scand. 2006;84:148-9.

23. Aguilar AJ. Comparative study of clinical efficacy and tolerance in seasonal allergic conjunctivitis management with $0.1 \%$ olopatadine hydrochloride versus $0.05 \%$ ketotifen fumarate. Acta Ophthalmol Scand. 2000;78:52-5.

24. Leonardi A, Zafirakis P. Efficacy and comfort of olopatadine versus ketotifen ophthalmic solutions: a double-masked, environmental study of patient preference. Curr Med Res Opin. 2004;20:1167-73.

25. Lainer B, Finegold I, D'Arienzo P, Granet D, Ebstein AB, Ledgerwood GL: Clinical efficacy of olopatadine versus epinastine ophthalmic solution in the conjunctival allergen challenge model. Curr Med Res Opin. 2004;20:1227-33.

26. Lippert U, Moller A, Welker P, Artuc M, Henz BM. Inhibition of cytokine secretion from human leukemic mast cells and basophils by $\mathrm{H}_{1}$ and $\mathrm{H}_{2}$ receptor antagonists. Exp Dermatol. 2000;9:118-24.

27. Leonardi A, Quintieri L. Olopatadine: a drug for allergic conjunctivitis targeting the mast cell. Expert Opin Pharmacother. 2010;11(6):969-81. 
28. Guest JF, Clegg JP, Smith AF. Health economic impact of olopatadine compared to branded and generic sodium cromoglycate in the treatment of seasonal allergic conjunctivitis in the UK. Curr Med Res Opin. 2006;22(9):1777-85.
Cite this article as: Scandashree K, Patil M, Udaykumar P. Comparative study of the efficacy and safety of olopatadine eyedrops and sodium cromoglycate in clinical practice: a prospective study. Int J Basic Clin Pharmacol 2016;5:1764-9. 